\title{
Ginsenoside Rg1 alleviates lipopolysaccharide-induced neuronal damage by inhibiting NLRP1 inflammasomes in HT22 cells
}

\author{
YAODONG ZHANG ${ }^{1 *}$, SHIXIN DING ${ }^{2 *}$, YALI CHEN $^{2 *}$, ZHENGHAO SUN $^{2}$, JUNYAN ZHANG $^{2}$, \\ YULI HAN $^{2}$, XIANAN DONG ${ }^{2}$, ZHIRUI FANG $^{2}$ and WEIZU LI ${ }^{2}$ \\ ${ }^{1}$ Department of Pharmacy, The First People's Hospital of Xiaoshan District, Hangzhou, Zhejiang 311200; \\ ${ }^{2}$ Department of Pharmacology, Basic Medicine College, Key Laboratory of Anti-inflammatory and \\ Immunopharmacology, Ministry of Education, Anhui Medical University, Hefei, Anhui 230032, P.R. China
}

Received October 22, 2020; Accepted April 12, 2021

DOI: $10.3892 /$ etm.2021.10214

\begin{abstract}
Lipopolysaccharide (LPS) is a toxic component of cell walls of Gram-negative bacteria that are widely present in gastrointestinal tracts. Increasing evidence showed that LPS plays important roles in the pathogeneses of neurodegenerative disorders, such as Alzheimer's disease (AD). NADPH oxidase s2 (NOX2) is a complex membrane protein that contributes to the production of reactive oxygen species (ROS) in several neurological diseases. The NLRP1 inflammasome can be activated in response to an accumulation of ROS in neurons. However, it is still unknown whether LPS exposure can deteriorate neuronal damage by activating NOX2-NLRP1 inflammasomes. Ginsenoside Rg1 (Rg1) has protective effects on neurons, although whether Rg1 alleviates LPS-induced neuronal damage by inhibiting NOX2-NLRP1 inflammasomes remains unclear. In the present study, the effect of concentration gradients and different times of LPS exposure on neuronal damage was investigated in HT22 cells, and further observed the effect of Rg1 treatment on NOX2-NLPR1 inflammasome activation, ROS production and neuronal damage in LPS-treated HT22 cells. The results demonstrated that LPS exposure significantly induced NOX2-NLRP1 inflammasome activation, excessive production of ROS, and neuronal damage in HT22 cells. It was also shown that Rg1 treatment significantly decreased NOX2-NLRP1 inflammasome activation and ROS production and alleviated neuronal damage in LPS-induced HT22 cells. The present data suggested that $\mathrm{Rg} 1$ has protective effects on LPS-induced neuronal damage by inhibiting NOX2-NLRP1 inflammasomes in HT22 cells,
\end{abstract}

Correspondence to: Dr Weizu Li, Department of Pharmacology, Basic Medicine College, Key Laboratory of Anti-inflammatory and Immunopharmacology, Ministry of Education, Anhui Medical University, 81 Meishan Road, Hefei, Anhui 230032, P.R. China E-mail: liweizu@126.com

*Contributed equally

Key words: ginsenoside Rg1, lipopolysaccharide, reactive oxygen species, inflammation, Alzheimer's disease and Rg1 may be a potential therapeutic approach for delaying neuronal damage in AD.

\section{Introduction}

Alzheimer's disease (AD) is an age-associated neurodegenerative disease, where the main symptoms include progressive decline in cognitive function, memory, spatial discrimination and language ability, potentially accompanied by other neurological symptoms (1). Although AD has been characterized by its pathological features, including extracellular amyloid $\beta$ (A $\beta)$ deposition, intracellular neurofibrillary tangles (NFTs) and neuronal loss (2), there may be other influencing factors involved in the progression of AD. In AD brains, it has been reported that lipopolysaccharide (LPS) levels and E. coli K99 were increased and co-localized with $\mathrm{A} \beta_{1-40 / 42}$ in amyloid plaques and around vessels (3). A clinical study also reported that LPS levels in the brains of patients with AD were two to three times higher compared with those found in healthy elderly individuals (4). Therefore, LPS may be involved in neuronal damage in the progression of AD.

LPS is a toxic component of cell walls of Gram-negative bacteria, which are widely present in the gastrointestinal tracts of humans and animals. Increasing evidence shows that LPS plays important roles in the pathogeneses of neurodegenerative disorders, such as AD (5). As a pathogen-associated molecular patterns, LPS can be recognized by the toll-like receptor 4 (TLR4)/MD2 complex on the surface of cells. Microglial TLR4 is a key regulator of inflammation that may play an essential role in the complex pathophysiological process of AD (6). LPS-induced hyperactive TLR4 has been seen to contribute to microglial over-activation, followed by increased neuronal apoptosis in the cortex of APP/PS1 mice (6). Additionally, You et al (7) reported that LPS-induced hepcidin expression in astrocytes induced the apoptosis of neurons through iron accumulation in rats. However, it is still not completely understood whether LPS exposure induces neuronal damage directly. A recent study showed that LPS could induce inflammatory injury in a neuronal cell line, HT22, by downregulating microRNA-132 (8). Thus, it is speculated that LPS exposure may induce neuronal damage directly, but the precise mechanisms have not been fully elucidated. 
Oxidative stress and neuroinflammation have been reported to play an important role in the progression of AD. Excessive generation of reactive oxygen species (ROS) induces a disturbance in the oxidant/anti-oxidant balance and results in oxidative stress damage in cells (9). ROS-induced oxidative stress has been considered to be the main cause of various neurological diseases, such as AD and Parkinson's disease (PD) (10). Nicotinamide adenine dinucleotide phosphate oxidase (NADPH oxidase, NOX) is a major contributor to ROS generation in cells (11). NOX2 is extensively expressed in brain, especially in neurons, and is closely associated with the pathogeneses of several neurodegenerative diseases, such as AD and PD $(12,13)$. Inflammasomes are macromolecular complexes that play an important role in regulating inflammation. Growing evidence shows that the NOD-like receptor protein 1 (NLRP1) inflammasome is involved in the pathogenesis of various neurological diseases, such as AD (14). The NLRP1 inflammasome can regulate the secretion and maturation of pro-inflammatory cytokines, such as pro-interleukin(IL)-1 $\beta$ into the bioactive form of IL-1 $\beta$, leading to an inflammatory response (15). Ma et al (16) reported that NOX2 plays an important role in regulating NLRP3 inflammasome activation in the brain after traumatic brain injury. A previous study also indicated that NOX2-mediated ROS generation was involved in NLRP1 inflammasome activation, resulting in age-associated neuronal damage (17). Additionally, the latest study reported that LPS could increase the sensitivity of $\mathrm{H} 9 \mathrm{C} 2$ cells to high glucose (HG) and hypoxia/reoxygenation and aggravate HG- and hypoxia/reoxygenation-induced $\mathrm{H} 9 \mathrm{C} 2$ cell injury by increasing ROS accumulation and inducing NLRP3 inflammasome activation (18). Therefore, it was hypothesized that LPS exposure may induce NOX2-NLRP1 inflammasome activation, resulting in neuronal damage.

Ginseng is a traditional Chinese medicine that has been used for over 2,000 years as a nourishing drug for improving health conditions and delaying senescence. Ginsenoside Rg1 ( $\mathrm{Rg} 1$ ), a monomer of a tetracyclic triterpenoid derivative, is mainly extracted and purified from the root of ginseng (19). It has been reported that Rg1 has anti-oxidant, anti-inflammatory, anti-apoptotic and autophagic effects (20). A recent study showed that Rg1 could attenuate chronic, unpredictable, mild stress-induced, depressive-like effects in rats via the regulation of the nuclear factor (NF)-kB/NLRP3 pathway (21). It was also seen that $\operatorname{Rg} 1$ could protect primary astrocyte cultures against oxygen-glucose deprivation/reoxygenation (OGD/R)-induced injury, by decreasing ROS generation (22). A recent study also showed that Rg1 could alleviate age-associated neuronal damage by decreasing NOX2-mediated ROS generation and inhibiting NLRP1 inflammasome activation in neurons (23). Additionally, recent research reported that $\mathrm{Rg} 1$ had protective effects against LPS-induced cognitive deficits in rats (24). Nevertheless, the precise mechanism of $\operatorname{Rg} 1$ on LPS-induced neuronal damage has not been fully elucidated.

Tempol is a ROS scavenger that can promote the metabolism of ROS. Recently, studies reported that pretreatment with tempol significantly increased cell viability and anti-oxidant activity, and decreased ROS production and cyclooxygenase-2 expression (25). Apocynin, a NOX inhibitor, can inhibit NOX activation by interfering with the intracellular translocation of two cytosolic components, p47phox and p67phox (26). Both tempol and apocynin have been reported to inhibit inflammatory responses in age-associated kidney damage (27). In the present study, it was hypothesized that Rg1 could ameliorate LPS-induced neuronal damage by inhibiting NOX2-NLRP1 inflammasome activation. In the present study, the effect of LPS exposure on neuronal damage in HT22 cells, depending on the LPS exposure times and concentration gradients, was examined. The effect of $\operatorname{Rg} 1$, tempol and apocynin on NOX2-NLPR1 inflammasome activation and neuronal damage was also examined in HT22 cells.

\section{Materials and methods}

Cell culture and treatments. The HT22 cell line is a sub-line derived from parent HT4 cells that were originally immortalized from mouse hippocampal neuron primary cultures (28). HT22 cells were cultured in Dulbecco's Modified Eagle Medium (DMEM; Hyclone; Cytiva), supplemented with 10\% fetal bovine serum (FBS; Zhejiang Tianhang Biotechnology Co., Ltd.) and $1 \%$ penicillin-streptomycin (Beyotime Institute of Biotechnology), in a $5 \% \mathrm{CO}_{2}$ incubator (Thermo Fisher Scientific, Inc.) at $37^{\circ} \mathrm{C}$. The cells were cultured for $24 \mathrm{~h}$ before being treated with LPS (Sigma-Aldrich; Merck KGaA), Rg1 (content of Rg1 >98\%; Chengdu Desite Biotechnology Co.), apocynin (Merck KGaA) or tempol (Merck KGaA). For exploration of the effect of LPS at different concentrations, HT22 cells were randomly divided into 5 groups and treated for $24 \mathrm{~h}$, as follows: No-LPS control, $5 \mathrm{mg} / \mathrm{l} \mathrm{LPS}, 10 \mathrm{mg} / \mathrm{l} \mathrm{LPS}$, $20 \mathrm{mg} / \mathrm{l} \mathrm{LPS}$, and $40 \mathrm{mg} / 1 \mathrm{LPS}$. For exploration of the effect of different lengths of LPS exposure, HT22 cells were randomly divided into 6 groups: No-LPS 12, 24 and $48 \mathrm{~h}$ control groups and LPS (10 mg/l)-treated 12, 24 and $48 \mathrm{~h}$ groups. For investigation of the effect of Rg1, HT22 cells were randomly divided into 6 groups and treated for $24 \mathrm{~h}$, as follows: No-LPS control, $10 \mathrm{mg} / 1 \mathrm{LPS}$ only, $10 \mathrm{mg} / 1 \mathrm{LPS}+\operatorname{Rg} 1(1,5$ or $10 \mu \mathrm{M}$ of $\mathrm{Rg} 1)$, $10 \mathrm{mg} / 1 \mathrm{LPS}+50 \mu \mathrm{M}$ tempol, $10 \mathrm{mg} / 1 \mathrm{LPS}+50 \mu \mathrm{M}$ apocynin . All experiments were repeated three times.

Measurement of lactate dehydrogenase ( $L D H)$. To observe the effect of Rg1 on LPS-induced neuronal damage in HT22 cells, the activity of LDH released to the medium was detected using an LDH kit (Nanjing KeyGen Biotech Co., Ltd.), according to the manufacturer's protocol. The cells were seeded into 96-well plates $\left(5 \times 10^{3}\right.$ cells per well). When the cells reached $\sim 60-70 \%$ confluence, they were treated with LPS or Rg1 $(1,5$ or $10 \mu \mathrm{M})$, tempol $(50 \mu \mathrm{M})$ or apocynin $(50 \mu \mathrm{M})$. Briefly, the supernatant was collected and reacted with nicotinamide adenine dinucleotide (NAD) and lactate solution at $37^{\circ} \mathrm{C}$ for $5 \mathrm{~min}$. The absorbance was detected at $490 \mathrm{~nm}$ with a Multiskan $^{\text {TM }}$ FC microplate reader (Thermo Fisher Scientific, Inc.) to calculate the activity of LDH.

Measurement of ROS production. ROS production was detected by a $\mathrm{H}_{2}$ DCFDA-Cellular ROS Assay kit (Nanjing KeyGen Biotech Co., Ltd.), according to the manufacturer's protocol. The cells were seeded into 24 -well plates $\left(1 \times 10^{5}\right.$ cells per well). When the cells reached $\sim 60-70 \%$ confluence, they were treated with LPS or $\operatorname{Rg} 1(1,5$ or $10 \mu \mathrm{M})$, tempol $(50 \mu \mathrm{M})$ or apocynin $(50 \mu \mathrm{M})$. For ROS detection, the $\mathrm{H}_{2}$ DCFDA stock solution was diluted with serum-free DMEM medium 
at a ratio of $1: 1,000$, to prepare a $10-\mu \mathrm{M}$ working solution of $\mathrm{H}_{2}$ DCFDA. Then, the $\mathrm{H}_{2}$ DCFDA working solution was added to the medium and incubated at $37^{\circ} \mathrm{C}$ for $30 \mathrm{~min}$. After incubation, the adherent cells were washed with PBS 3 times (5 min per wash) and the results were examined at 488/525 nm excitation/emission using fluorescence microscopy (Olympus IX71; Olympus Corporation). The mean fluorescence intensities from three wells and five random fields (magnification, x200) per well were obtained using Image Pro Plus 6.0 (Media Cybernetics, Inc.) automatic image analysis software to indicate the changes in ROS production.

Apoptosis assay. To confirm neuronal damage, cell apoptosis was detected using the Annexin V-FITC/PI Apoptosis Detection kit (Beyotime Institute of Biotechnology), according to the manufacturer's protocol. The cells were seeded into 24 -well plates $\left(1.0 \times 10^{5}\right.$ cells per well). When the cells reached $\sim 60-70 \%$ confluence, they were treated with LPS or Rg1 $(1,5$ or $10 \mu \mathrm{M})$, tempol $(50 \mu \mathrm{M})$ or apocynin $(50 \mu \mathrm{M})$. For Annexin V-FITC/PI staining, the cells were washed twice with PBS (5 min per wash) then incubated with binding buffer for $15 \mathrm{~min}$ at room temperature. Next, the cells were incubated with Annexin V-FITC (5 $\mu \mathrm{l} /$ well) and propidium iodide (PI; $10 \mu \mathrm{l} /$ well) for $15 \mathrm{~min}$ at room temperature. The results were detected for Annexin V-FITC (excitation/emission, 488/530 nm) and PI (excitation/emission, 488/630 nm) by fluorescence microscopy (Olympus IX71; Olympus Corporation). Positively stained areas were analyzed from three wells and five random fields (magnification, x200) per well by the Image-Pro Plus 6.0 automatic image analysis software. The mean density of Annexin V-FITC-positive areas was examined to assess early apoptotic cells, and the mean density of PI-positive areas was examined to assess late apoptotic cells

Western blotting. Western blotting was performed to detect the levels of $\beta$-galactosidase ( $\beta$-Gal), NLRP1, cleaved caspase-1, IL-1 $\beta$, NF- $\kappa$ B, phosphorylated (p)-NF- $\mathrm{B}$, p47phox, p22phox, NOX2, Bax, Bcl-2 and cleaved caspase-3 proteins. The cells were seeded into 6 -well plates $\left(5.0 \times 10^{5}\right.$ cells per well). When the cells reached $\sim 60-70 \%$, they were treated with LPS or Rg1 $(1,5$ or $10 \mu \mathrm{M})$, tempol $(50 \mu \mathrm{M})$ or apocynin $(50 \mu \mathrm{M})$ for $24 \mathrm{~h}$. The total protein was extracted by a mixture of RIPA lysis buffer (Beyotime Institute of Biotechnology) with phenylmethanesulfonyl fluoride (Beyotime Institute of Biotechnology) and phosphatase inhibitors (Beyotime Institute of Biotechnology) at 100:1:1. The protein concentration was determined using the BCA Protein Assay kit (Beyotime Institute of Biotechnology). Equal amounts of protein $(30 \mu \mathrm{g})$ were separated by $12 \%$ SDS-polyacrylamide gel electrophoresis and transferred onto polyvinylidene fluoride membranes (Merck KGaA). The membranes were blocked with $5 \%$ skimmed milk for $1 \mathrm{~h}$ at room temperature. The membranes were then washed 3 times (10 min per wash) using Tris-buffered saline with $0.05 \%(\mathrm{v} / \mathrm{v})$ Tween-20 (TBST) and incubated overnight at $4{ }^{\circ} \mathrm{C}$ with the primary antibodies for $\beta$-Gal $(1: 1,000$; cat. no. WL03124; Wanleibio Co., Ltd.), NLRP1 (1:1,000; cat. no. ab3683; Abcam), caspase-1 (1:1,000; cat. no. AF0120; Affinity Biosciences), IL-1 $\beta$ (1:1,000; cat. no. AF5130; Affinity Biosciences), NF- $\kappa$ B (1:1,000; cat. no. AF5130; Wanleibio
Co., Ltd.), p-NF-кB (1:1,000; cat. no. GB11142-1; Wuhan Servicebio Technology Co., Ltd.), p47phox (1:1,000; cat. no. BS4852; Bioworld Biotechnology, Inc.), p22phox (1:1,000; cat. no. BS60290; Bioworld Biotechnology, Inc.), NOX2 (1:1,000; cat. no. ab31092; Abcam), Bax (1:1,000; AF0120; Affinity Biosciences), Bcl-2 (1:1,000; cat. no. AF6139; Affinity Biosciences), cleaved caspase-3 (1:1,000; cat. no. BS7003; Bioworld Technology, Inc.) and $\beta$-actin (1:1,000; cat. no. TA-09; OriGene Technologies, Inc.). The membranes were then incubated for $1 \mathrm{~h}$ at $25^{\circ} \mathrm{C}$ with either horseradish peroxidase-conjugated goat anti-rabbit (1:10,000; cat. no. ZB-2301; OriGene Technologies, Inc.) or goat anti-mouse (1:10,000; cat. no. ZB-2305; OriGene Technologies, Inc.) secondary antibodies. The membranes were incubated with ECL substrate kit (Bio-Rad Laboratories, Inc.) and the bands were visualized using a Bioshine Chemi Q4600 Mini Imaging System (Shanghai Bioshine Technology). ImageJ 1.46R software (National Institutes of Health) was used to detect the density of immunoreactive bands. The relative density of each target protein compared to the control was used to represent the changes in target protein expression levels.

Statistical analysis. Data are presented as the mean \pm standard deviation (SD). The statistical analysis was performed using GraphPad Prism 6.0 software (GraphPad Software, Inc.). Differences among the experimental groups were evaluated using one-way analysis of variance (ANOVA) followed by Tukey's multiple comparisons test to compare the differences between groups. $\mathrm{P}<0.05$ was considered to indicate a statistically significant difference.

\section{Results}

Effects of Rgl on LPS-induced LDH release and $\beta$-Gal expression in HT22 cells. The effects of LPS exposure on LDH release from HT22 cells were firstly observed. The results showed that $\mathrm{LDH}$ release was significantly increased in LPS-treated $(5,10,20$ or $40 \mathrm{mg} / \mathrm{l})$ groups compared with the control group (Fig. 1A; P<0.01). LPS (10 mg/l) treatment for 12,24 or $48 \mathrm{~h}$ also significantly increased the $\mathrm{LDH}$ release compared with the control group (Fig. $1 \mathrm{~B} ; \mathrm{P}<0.01$ ). The results suggested that LPS exposure significantly induced neuronal damage in HT22 cells.

The effects of Rg1 treatment on LPS-induced LDH release in HT22 cells were further observed. The results showed that LPS $(10 \mathrm{mg} / \mathrm{l})$ treatment for $24 \mathrm{~h}$ significantly increased the LDH release in HT22 cells compared with the control group (Fig. 1C; $\mathrm{P}<0.01)$. Treatment with $\operatorname{Rg} 1$ (5 or $10 \mu \mathrm{M})$ significantly decreased the LDH release (Fig. 1C; $\mathrm{P}<0.01)$ compared with the LPS-treated (10 mg/l) group. Meanwhile, treatment with tempol $(50 \mu \mathrm{M})$ and apocynin $(50 \mu \mathrm{M})$ also significantly decreased the LDH release from HT22 cells (Fig. 1C; $\mathrm{P}<0.01$ ). The results indicated that Rg1 significantly decreased LDH release and protected against LPS-induced neuronal damage in HT22 cells.

The accumulation of senescence-associated $\beta-\mathrm{Gal}$ is an important senescence marker (29). To observe the effect of Rg1 on LPS-induced senescence in HT22 cells, the expression of senescence-associated $\beta$-Gal was detected by western blotting. The results showed that LPS (10 mg/l) exposure for $24 \mathrm{~h}$ 
A

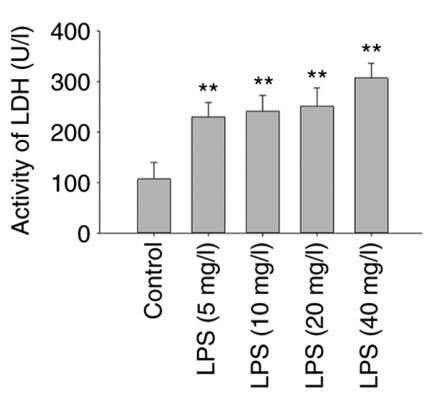

C

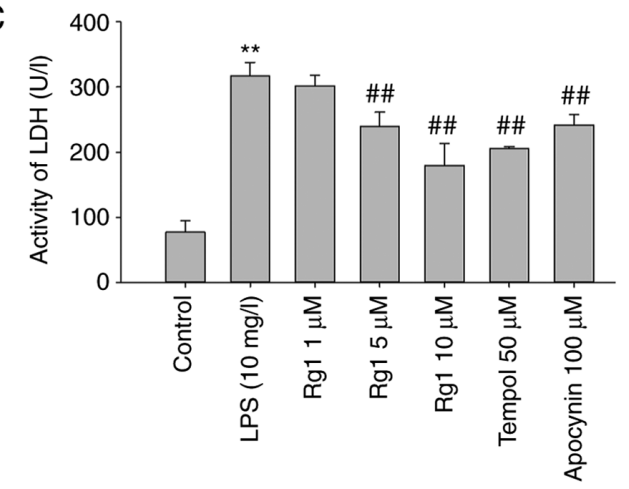

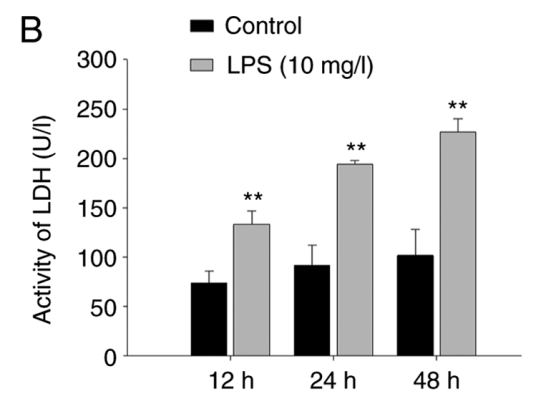

D

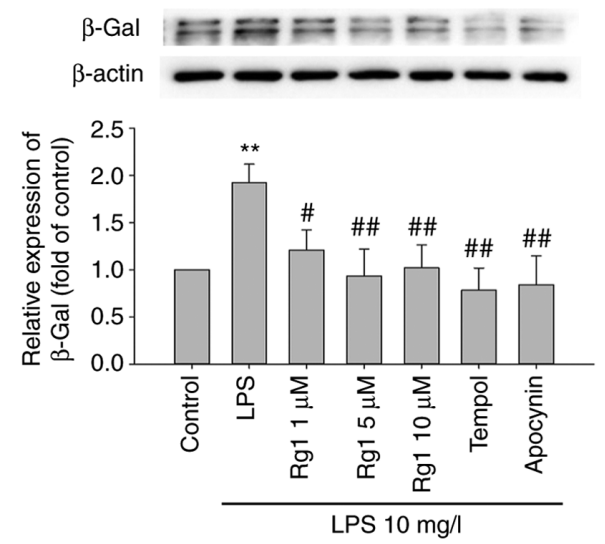

Figure 1. Effects of Rg1 on LDH release and $\beta$-Gal expression in LPS-induced HT22 cells. (A) The effects of LPS (5, 10, 20 and 40 mg/l) on LDH release in HT22 cells. (B) The effects of LPS (10 mg/l)-treated HT22 cells (for 12, 24 and $48 \mathrm{~h}$ ) on LDH release. (C) The effects of Rg1 treatment on LDH release in LPS-induced HT22 cells. LDH release was determined using an LDH kit. (D) The effects of Rg1 on $\beta$-Gal expression in LPS-treated HT22 cells determined by western blotting. Results are expressed as mean $\pm \mathrm{SD}, \mathrm{n}=3$. ${ }^{* *} \mathrm{P}<0.01$ vs. control group. ${ }^{\#} \mathrm{P}<0.05 ;{ }^{\# \#} \mathrm{P}<0.01$ vs. LPS (10 mg/l) group. Rg1, ginsenoside Rg1; $\beta$-Gal, $\beta$-Galactosidase; LDH, lactate dehydrogenase; LPS, lipopolysaccharide.

significantly increased $\beta$-Gal expression compared with the control group in HT22 cells (Fig. 1D; $\mathrm{P}<0.01$ ). Compared with the LPS-treated $(10 \mathrm{mg} / \mathrm{l})$ group, the expression of $\beta$-Gal was significantly decreased in $\operatorname{Rg} 1(1,5$ or $10 \mu \mathrm{M})$, tempol $(50 \mu \mathrm{M})$ and apocynin $(50 \mu \mathrm{M})$ groups (Fig. $1 \mathrm{D} ; \mathrm{P}<0.01$ or $\mathrm{P}<0.05)$. The data suggested that $\operatorname{Rg} 1$ treatment delays LPS-induced senescence of HT22 cells.

Effects of Rg1 on ROS generation in LPS-induced HT22 cells. ROS-mediated oxidative stress plays an important role in several neurodegenerative diseases. To identify the effects of LPS on ROS generation in HT22 cells, $\mathrm{H}_{2}$ DCFDA fluorescence staining was performed to examine the levels of ROS. The results showed that the levels of ROS production were significantly increased in LPS-treated $(10,20$ or $40 \mathrm{mg} / \mathrm{l})$ groups compared with the control group (Fig. $2 \mathrm{~A}$ and $\mathrm{B} ; \mathrm{P}<0.01$ ). Meanwhile, the results showed that the ROS production was increased in the control group and LPS-treated groups when cultured for a prolonged period. However, compared with the control group, groups treated with LPS (10 mg/1) for 12, 24 and $48 \mathrm{~h}$ showed significant increases in the ROS levels, especially at $24 \mathrm{~h}$ (Fig. 2C and D; P<0.01). Although LPS exposure for $48 \mathrm{~h}$ further increased ROS production compared with exposure for $24 \mathrm{~h}$, the relative ROS production was decreased due to the increase in ROS production in the control group. These results suggested that LPS exposure could significantly increase ROS generation in HT22 cells.

The effects of Rg1 treatment on ROS generation was further observed in LPS-induced HT22 cells. The results showed that LPS $(10 \mathrm{mg} / \mathrm{l})$ treatment for $24 \mathrm{~h}$ significantly increased the levels of ROS production in HT22 cells compared with the control group (Fig. 2E and F; $\mathrm{P}<0.01$ ). Compared with the LPS-treated $(10 \mathrm{mg} / \mathrm{l})$ group, treatment with $\operatorname{Rg} 1(1,5$ or $10 \mu \mathrm{M})$ significantly decreased the levels of ROS (Fig. 2E and F; $\mathrm{P}<0.01)$. Meanwhile, treatment with tempol $(50 \mu \mathrm{M})$ or apocynin $(50 \mu \mathrm{M})$ also significantly decreased the levels of ROS in HT22 cells (Fig. 2E and F; P<0.01). The data suggested that Rg1 could significantly decrease ROS generation and could protect against LPS-induced oxidative stress damage in HT22 cells.

Effects of Rg1 on the expression of NOX2, p22phox and p47phox in LPS-induced HT22 cells. To confirm whether Rg1 could decrease ROS generation in LPS-induced HT22 cells by inhibiting NOX2, the expression of NOX2, p22phox and p47phox levels were detected by western blotting. The results showed that the expression of NOX2, p22phox and p47phox were significantly increased in the LPS-treated $(10 \mathrm{mg} / \mathrm{l})$ group compared with the control group (Fig. 3A-D; $\mathrm{P}<0.05$ or $\mathrm{P}<0.01$, respectively). Compared with the LPS-treated $(10 \mathrm{mg} / \mathrm{l})$ group, treatment with $\operatorname{Rg} 1(1,5$ or $10 \mu \mathrm{M})$, tempol $(50 \mu \mathrm{M})$ or apocynin $(50 \mu \mathrm{M})$ significantly decreased the expression of NOX2 and p47phox (Fig. 3A and $\mathrm{C} ; \mathrm{P}<0.05$ and $\mathrm{P}<0.01$, respectively). Meanwhile, treatment with $\mathrm{Rg} 1$ $(10 \mu \mathrm{M})$ or apocynin $(50 \mu \mathrm{M})$ significantly decreased the expression of p22phox in LPS-induced HT22 cells (Fig. 3B; $\mathrm{P}<0.05$ and $\mathrm{P}<0.01$, respectively). These data suggest that LPS exposure-induced ROS generation might be associated with the activation of NOX2, and that $\mathrm{Rg} 1$ could significantly 
A
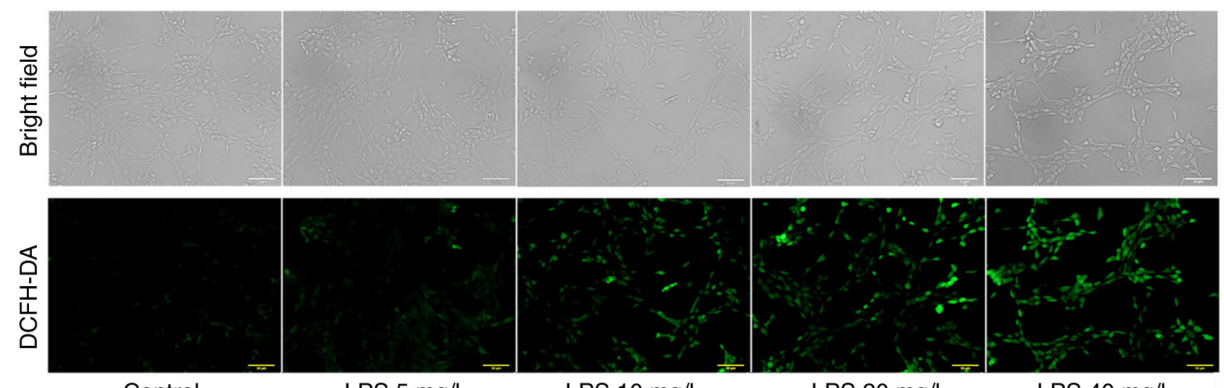

Control

LPS $5 \mathrm{mg} / \mathrm{l}$

LPS $10 \mathrm{mg} / \mathrm{l}$

LPS 20 mg/l

LPS $40 \mathrm{mg} / \mathrm{l}$
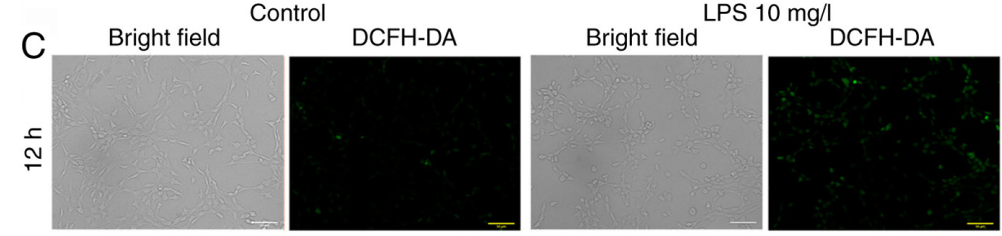

$\mathrm{B} \underset{\square}{\infty}$ 응 80
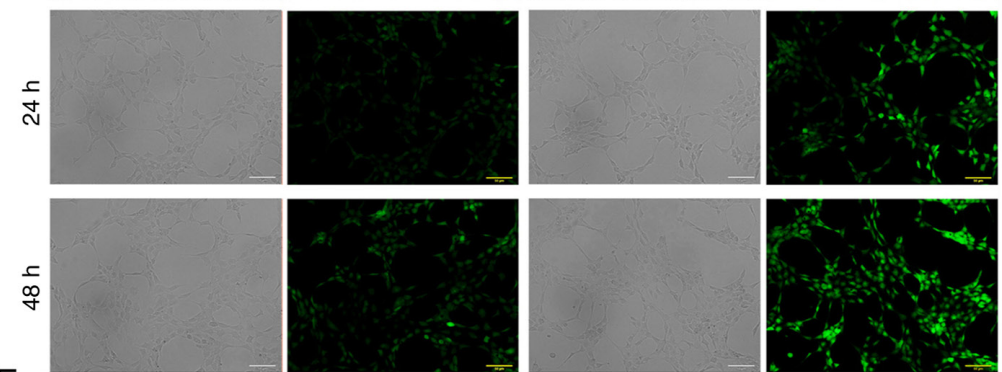

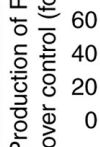

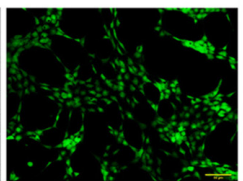

D
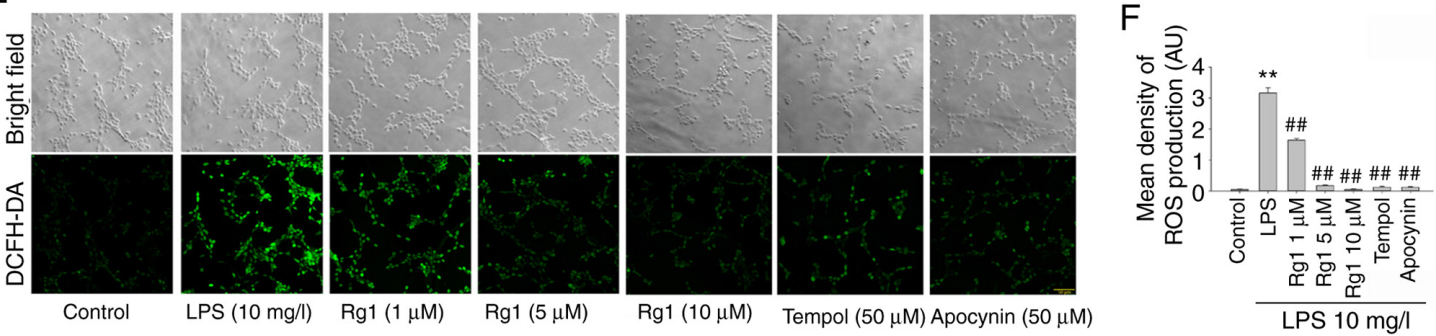

Figure 2. Effects of Rg1 on ROS generation in LPS-induced HT22 cells. (A) The effects of LPS (5, 10, 20 and 40 mg/l) exposure on ROS generation in HT22 cells. (B) Quantitative analysis of LPS (5, 10, 20 and $40 \mathrm{mg} / \mathrm{l})$ exposure on ROS production compared with the control. (C) The effects of LPS (10 mg/l) exposure for 12, 24 and $48 \mathrm{~h}$ on ROS generation in HT22 cells. (D) Quantitative analysis of LPS (10 mg/l) exposure for 12,24 and 48 h on ROS production compared with the control. (E) The effects of Rg1 on ROS production in LPS-induced HT22 cells. (F) Quantitative analysis of the levels of ROS production. H2DCFDA staining; magnification, $\mathrm{x} 200$, scale bars, $50 \mu \mathrm{m}$. Results are expressed as mean $\pm \mathrm{SD}, \mathrm{n}=3$. ${ }^{* *} \mathrm{P}<0.01$ vs. control group. ${ }^{\# \#} \mathrm{P}<0.01 \mathrm{vs}$. LPS $(10 \mathrm{mg} / \mathrm{l})$ group. Rg1, ginsenoside Rg1; ROS, reactive oxygen species; LPS, lipopolysaccharide.

decrease NOX2 expression and decrease ROS generation in LPS-induced HT22 cells.

Effects of Rg1 on the expression of NLRP1, caspase-1, IL-1 $N F-\kappa B$ and $p-N F-\kappa B$ in LPS-induced HT22 cells. The elevation of ROS production is involved in NLRP1 inflammasome activation, which plays an important role in neurodegenerative diseases. To confirm whether Rg1 treatment could protect against LPS-induced neuronal damage by inhibiting NLRP1 inflammasome activation, the expression of NLRP1, cleaved caspase-1, IL-1 $\beta, N F-\kappa B$ and $p-N F-\kappa B$ was investigated in LPS-induced HT22 cells. The results showed that LPS $(10 \mathrm{mg} / \mathrm{l})$ exposure significantly increased the expression of NLRP1, cleaved caspase-1, IL- $1 \beta, N F-\kappa B$ and $p-N F-\kappa B$, in comparison to the control group (Fig. 4A-F; $\mathrm{P}<0.05$ and $\mathrm{P}<0.01$, respectively). When compared with the LPS-treated group, treatment with $\operatorname{Rg} 1(5$ or $10 \mu \mathrm{M})$ and apocynin $(50 \mu \mathrm{M})$ significantly decreased the expression of NLRP1 (Fig. 4A and B; P<0.01). Treatment with $\operatorname{Rg} 1(5$ or $10 \mu \mathrm{M})$, tempol $(50 \mu \mathrm{M})$ or apocynin
$(50 \mu \mathrm{M})$ also significantly decreased the expression of cleaved

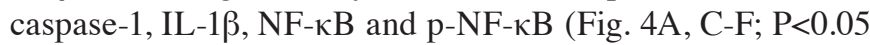
and $P<0.01$, respectively). Since the expression levels of $N F-\kappa B$ and $\mathrm{p}-\mathrm{NF}-\kappa \mathrm{B}$ were increased in the LPS group and decreased in $\mathrm{Rg} 1$, tempol or apocynin groups, the relative expression of $\mathrm{p}-\mathrm{NF}-\kappa \mathrm{B} / \mathrm{NF}-\kappa \mathrm{B}$ has an increasing trend only in the LPS group and a decreasing trend in the Rg1 group. The aforementioned results indicated that activation of the NLRP1 inflammasome was involved in LPS exposure-induced neuronal damage. The aforementioned results also suggest that Rg1 might protect against LPS-induced HT22 cells damage by inhibiting the expression of the NLRP1 inflammasome.

Effects of Rgl on LPS-induced apoptosis in HT22 cells. Neuronal apoptosis is involved in the pathogenesis of neurodegenerative diseases. To confirm the protective effect of $\mathrm{Rg} 1$ on LPS-induced neuronal damage, the effect of $\mathrm{Rg} 1$ on LPS-induced apoptosis was observed by Annexin V FITC/PI staining in HT22 cells. The results showed that LPS (10 mg/l) 
A

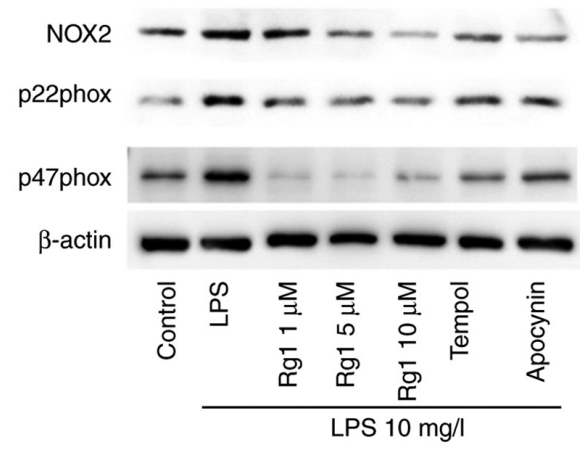

C

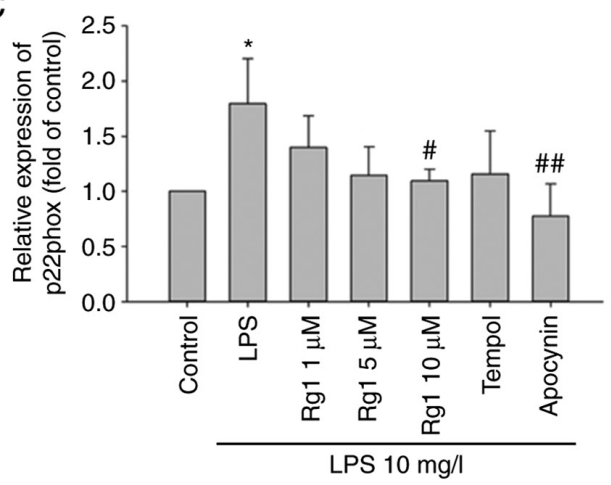

B

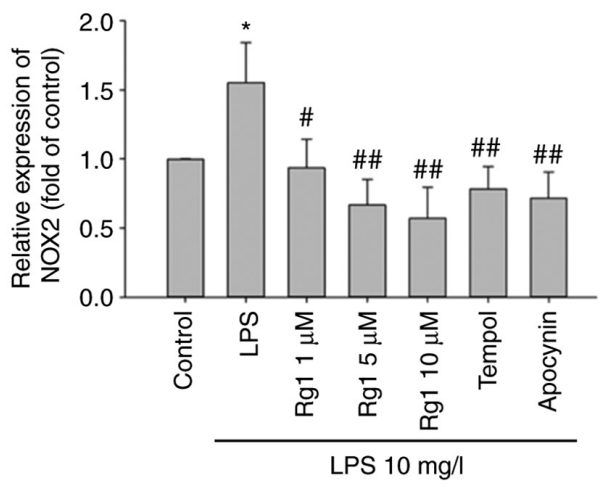

D

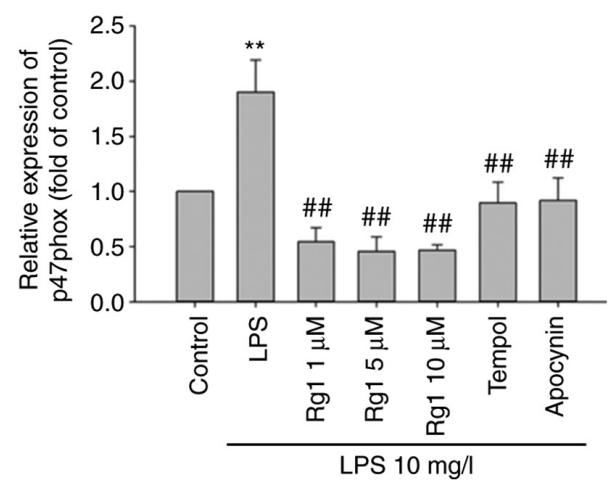

Figure 3. Effects of Rg1 on the expression levels of NOX2, p22phox and p47phox in LPS-induced HT22 cells determined by western blotting. (A) The bands of NOX2, p22phox and p47phox in LPS-induced HT22 cells. Quantitative analysis of (B) NOX2, (C) p22phox and (D) p47phox expression levels relative to the control. Results are expressed as mean $\pm \mathrm{SD}, \mathrm{n}=3 .{ }^{*} \mathrm{P}<0.05 ;{ }^{* *} \mathrm{P}<0.01$ vs. control group. ${ }^{\#} \mathrm{P}<0.05 ;{ }^{\# \prime} \mathrm{P}<0.01$ vs. LPS (10 mg/l) group. Rg1, ginsenoside Rg1; LPS, lipopolysaccharide; NOX2, NAPDH oxidase 2.

exposure for $24 \mathrm{~h}$ significantly increased both the early and late apoptotic cells, in comparison to the control group (Fig. 5A-C; $\mathrm{P}<0.01)$. Compared with the LPS-treated $(10 \mathrm{mg} / \mathrm{l})$ group, treatment with Rg1 (5 or $10 \mu \mathrm{M})$, tempol $(50 \mu \mathrm{M})$ or apocynin $(50 \mu \mathrm{M})$ significantly decreased the early apoptotic cells (Fig. 5A and B; $\mathrm{P}<0.01$ ). However, treatment with Rg1, tempol or apocynin had no significant effect on the late apoptotic cells (Fig. 5A and C; P>0.05). The aforementioned data indicated that Rg1 could effectively alleviate LPS-induced apoptosis in HT22 cells.

Effects of Rgl on the expression of Bax, Bcl-2 and cleaved caspase-3 in LPS-induced HT22 cells. The effect of Rg1 was investigated on the expression of apoptosis-associated proteins Bax, Bcl-2 and cleaved caspase-3, in LPS-induced HT22 cells. The results showed that LPS (10 mg/l) exposure for $24 \mathrm{~h}$ significantly increased the expression of Bax and cleaved caspase-3, and significantly decreased Bcl-2 expression, in comparison to the control group (Fig. 6A-D; P<0.01). When compared with the LPS-treated $(10 \mathrm{mg} / \mathrm{l})$ group, treatment with $\operatorname{Rg} 1(5$ or $10 \mu \mathrm{M})$, tempol $(50 \mu \mathrm{M})$ or apocynin $(50 \mu \mathrm{M})$ significantly decreased the expression levels of Bax and cleaved caspase-3 expressions (Fig. 6A-D; $\mathrm{P}<0.05$ or $\mathrm{P}<0.01)$. Meanwhile, $\operatorname{Rg} 1(5$ or $10 \mu \mathrm{M})$ and tempol treatment significantly increased Bcl-2 expression level (Fig. 6A and B; $\mathrm{P}<0.05$ and $\mathrm{P}<0.01$, respectively). The results suggested that sRg1 could alleviate LPS-induced apoptosis by regulating the expression of Bax, Bcl-2 and cleaved caspase-3 in HT22 cells.

\section{Discussion}

Although AD has been characterized by its pathological features, such as A $\beta$ deposition, NFTs and neuron loss, LPS is also involved in the progression of AD. The effects of Rg1 are associated to its properties, such as its anti-oxidant effects and ability to inhibit inducible nitric oxide synthase (iNOS) expression and nitric oxide (NO) overgeneration (30). In addition, $\operatorname{Rg} 1$ has been reported to attenuate LPS-induced inflammatory responses in murine BV-2 microglial cells (31). However, whether Rg1 can alleviate LPS-induced neuronal damage and its precise mechanism of action needs to be further investigated. In the present study, the results demonstrated that LPS exposure could significantly induce NOX2 and NLRP1 inflammasome activation, resulting in neuronal damage and apoptosis in HT22 cells. More importantly, Rg1 treatment could significantly decrease the expression of NOX2 and NLRP1 inflammasomes, decrease ROS and cytokine generation, and alleviate neuronal damage and apoptosis in LPS-induced HT22 cells. Meanwhile, the results showed that treatment with tempol (a ROS scavenger) and apocynin (a NOX inhibitor) also significantly decreased the expression of NOX2 and NLRP1 inflammasomes and alleviated neuronal damage and apoptosis in LPS-induced HT22 cells. These findings suggest that NOX2 expression and NLRP1 inflammasome activation is closely associated with LPS-induced neuronal damage, and that Rg1 treatment can protect against LPS-induced neuronal damage by inhibiting NOX2-NLRP1 inflammasomes in HT22 cells. 

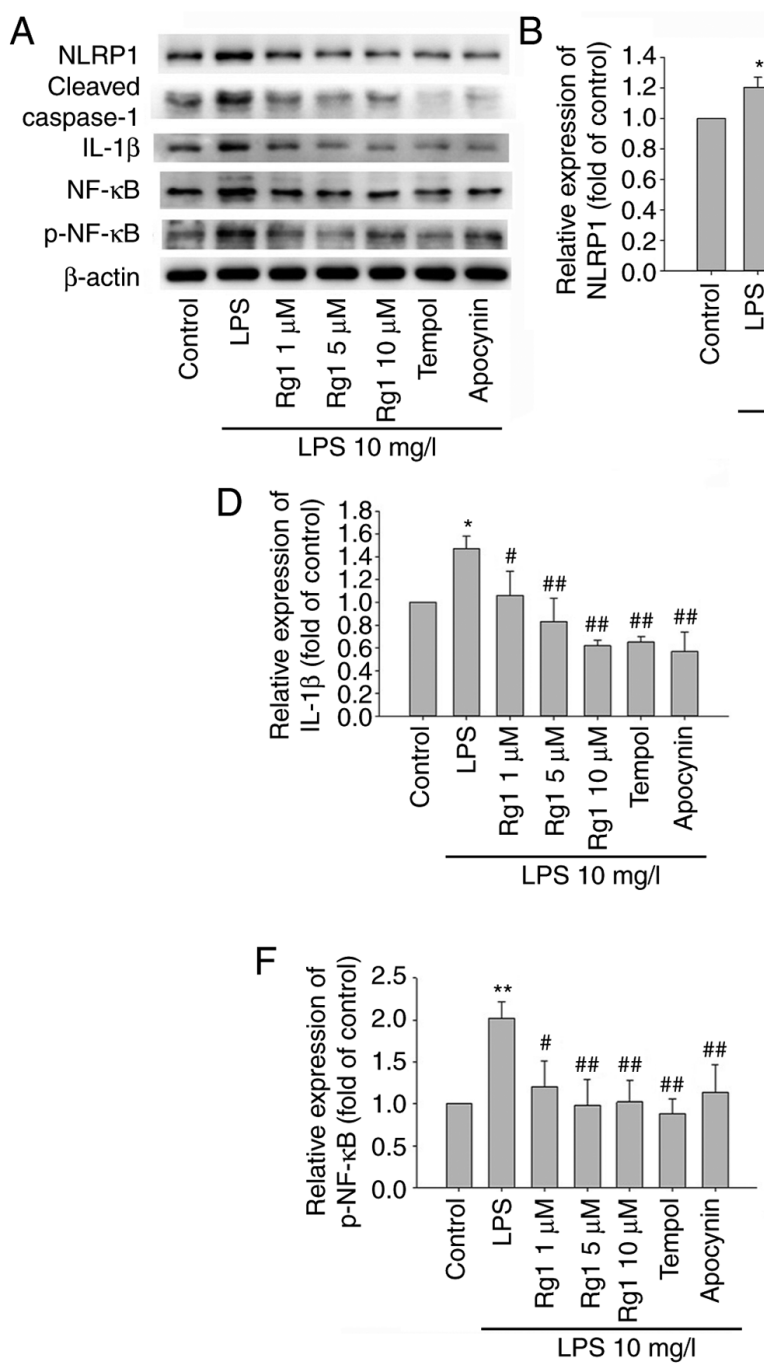
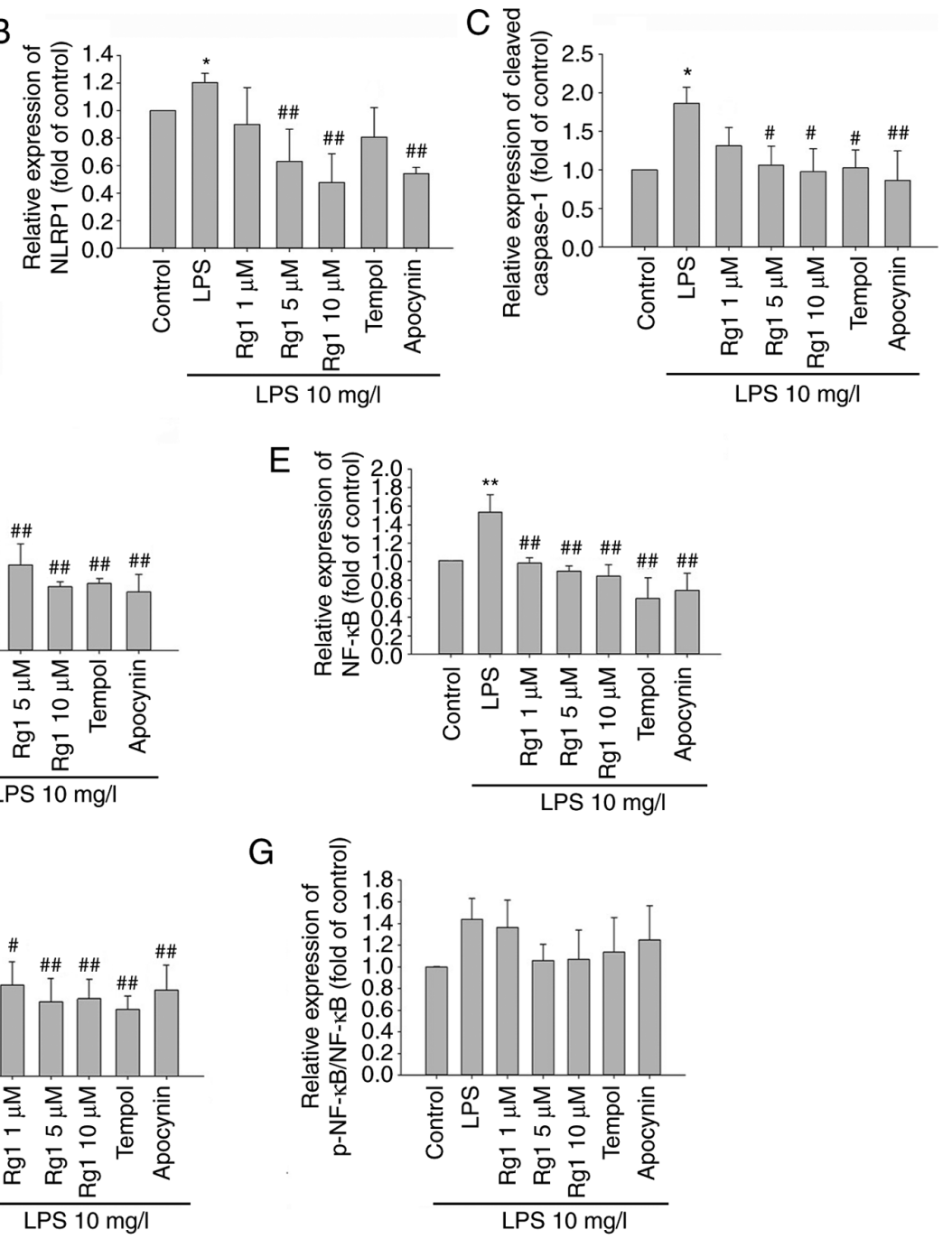

Figure 4. Effects of Rg1 on the expression levels of NLRP1, cleaved-caspase-1, IL-1 $\beta$, NF- $\kappa$ B and p-NF- $\kappa$ B in LPS-induced HT22 cells determined by western blotting. (A) The bands of NLRP1, cleaved-caspase-1, IL-1 $\beta, N F-\kappa B$ and p-NF- $\mathrm{B}$ in LPS-induced HT22 cells. Quantitative analysis of (B) NLRP1, (C) cleaved-caspase-1, (D) IL-1 $\beta$, (E) NF- $\kappa \mathrm{B},(\mathrm{F}) \mathrm{p}-\mathrm{NF}-\kappa \mathrm{B}$ expression levels relative to the control and (G) p-NF- $\kappa \mathrm{B} / \mathrm{NF}-\kappa \mathrm{B}$. Results are expressed as mean $\pm \mathrm{SD}, \mathrm{n}=3$. * $\mathrm{P}<0.05 ;{ }^{* *} \mathrm{P}<0.01$ vs. control group. ${ }^{\#} \mathrm{P}<0.05$; ${ }^{\# \#} \mathrm{P}<0.01$ vs. LPS $(10 \mathrm{mg} / \mathrm{l})$ group. Rg1, ginsenoside Rg1; LPS, lipopolysaccharide; IL, interleukin, $\mathrm{p}-$, phosphorylated-; NF- $\kappa \mathrm{B}$, nuclear factor- $\kappa \mathrm{B}$.

LPS is a bacterial cell wall endotoxin that can cause systemic inflammation and neuroinflammation through activation of the systemic or neurological immune system and generation of pro-inflammatory mediators, such as IL-I $\beta$, IL-6 and IL-8 $(32,33)$. LPS is composed of lipid A, a core oligosaccharide chain, and an O-antigenic polysaccharide side chain. LPS is commonly used as an inflammatory inducer and an oxidative stress stimulant in both in vitro and in vivo experiments to activate cells to produce various inflammatory components (34). Oxidative stress can damage the mitochondria and other cellular components of neurons (35), ultimately contributing to the pathogenesis of AD. LPS has also been used to stimulate ROS accumulation and induce neuronal damage (36). Overproduction of ROS participates in cell suicide, by initiating programmed cell death (apoptosis) pathways (37). In the present study, the results of LDH release indicated that HT22 cells were significantly damaged by increasing concentrations and times of LPS exposure. The results of $\mathrm{H}_{2}$ DCFDA staining showed that ROS production was significantly increased with increasing concentration and time of LPS exposure in HT22 cells. In addition, Annexin V FITC/PI staining showed that apoptotic cells were significantly increased in LPS-induced HT22 cells. These data indicated that LPS exposure could significantly increase ROS generation and cell apoptosis in HT22 cells, contributing to neuronal damage and becoming more serious with increasing concentration and time of LPS exposure.

Ginseng is a traditional Chinese medicine which has been used for thousands of years to improve the health of the elderly and delay ageing. Ginsenoside Rg1, a main active component, has neurotrophic, neuroprotective and anti-ageing effects, and it has often been used to prevent neuronal damage by inhibiting oxidative stress and inflammation $(38,39)$. Additionally, it has been reported that $\mathrm{Rg} 1$ has anti-senescence effects on neural stem cells and delays brain aging by activating the Wnt/ $\beta$-catenin signaling pathway (40). $\operatorname{Rg} 1$ can also protect PD mice (where PD is induced through continuous LPS injections) by inhibiting the nuclear entry of $\mathrm{NF}-\kappa \mathrm{B}$ and regulating the polarization balance of microglia (41). In the present study, the results showed that $\mathrm{Rg} 1$, tempol and apocynin treatments 
A
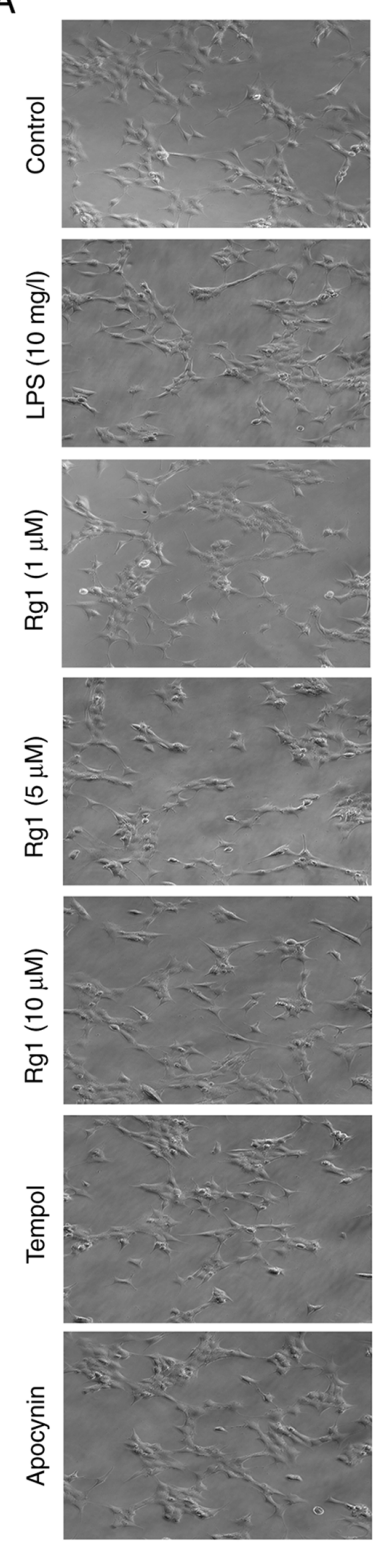

B

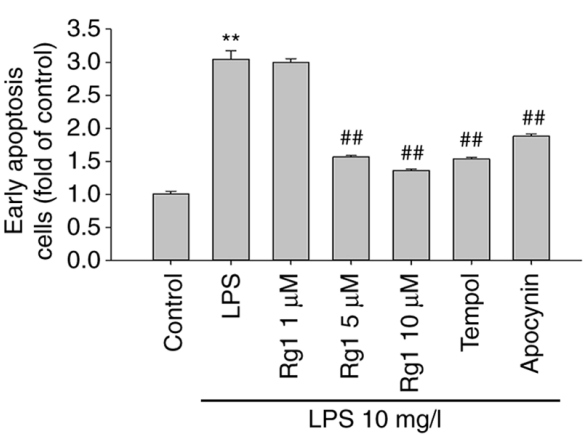

Annexin V-FITC
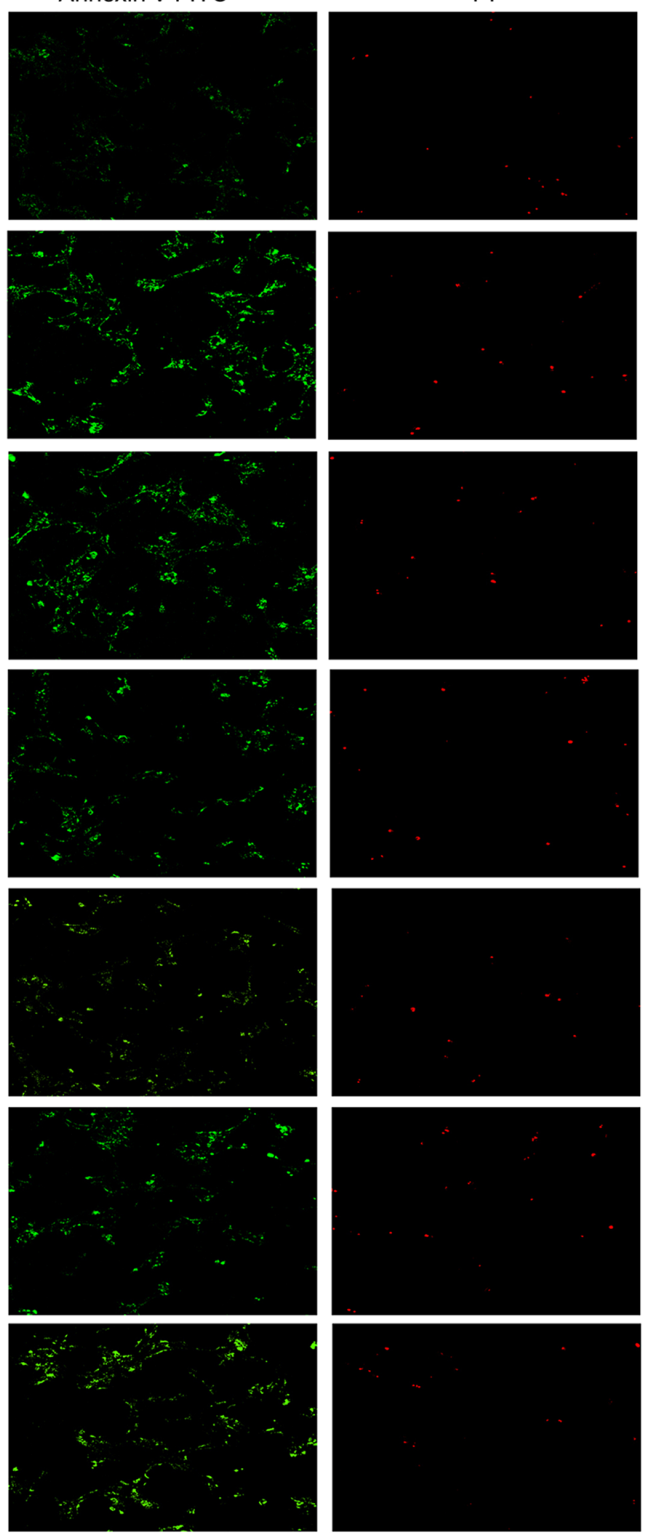

C

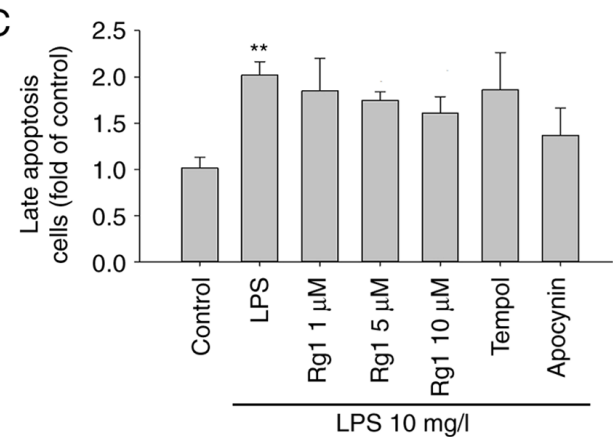

Figure 5. Effects of Rg1 on apoptosis in LPS-induced HT22 cells. (A) Apoptotic cells were detected by Annexin V-FITC/PI staining. Magnification, x200; scale bars, $50 \mu \mathrm{m}$. (B) Quantitative analysis of the early apoptotic cells relative to the control. (C) Quantitative analysis of the late apoptotic cells relative to the control. Results are expressed as mean $\pm \mathrm{SD}, \mathrm{n}=3 .{ }^{* *} \mathrm{P}<0.01$ vs. control group. ${ }^{\# \#} \mathrm{P}<0.01$ vs. LPS (10 mg/l) group. Rg1, ginsenoside Rg1; LPS, lipopolysaccharide.

significantly decreased LDH release, ROS generation and IL-1 $\beta$ expression compared with the LPS group in HT22 cells. Meanwhile, the results indicated that Rg1, tempol or apocynin treatments significantly inhibited the expression of $\beta$-Gal and alleviated LPS-induced cell apoptosis in HT22 cells. All these data suggest that $\operatorname{Rg} 1$ treatment could effectively protect against LPS-induced neuronal damage. However, the mechanism underlying the protective effects of $\operatorname{Rg} 1$ on LPS-induced neuronal damage remains to be fully elucidated.

NADPH oxidase (NOX) belongs to a group of electron-transporting transmembrane enzymes that contribute to ROS generation in many tissues (42) and it has been reported to be 
A

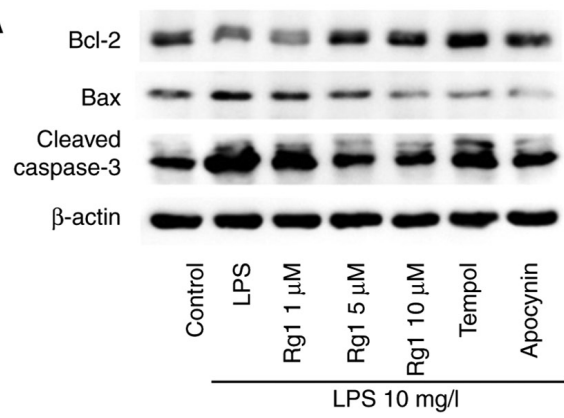

C

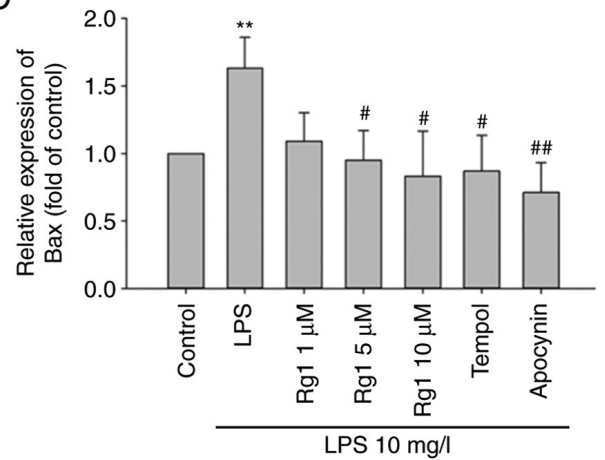

B

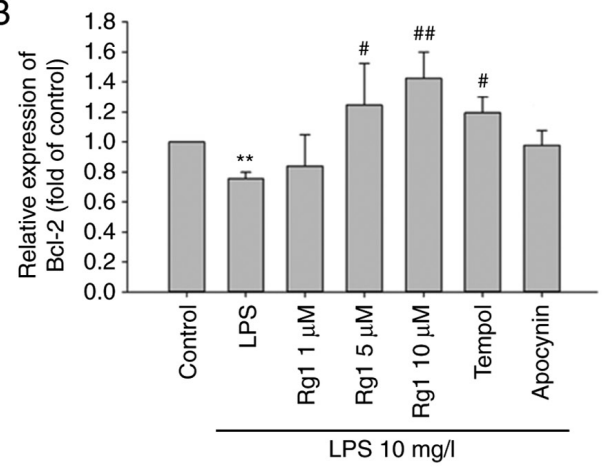

D

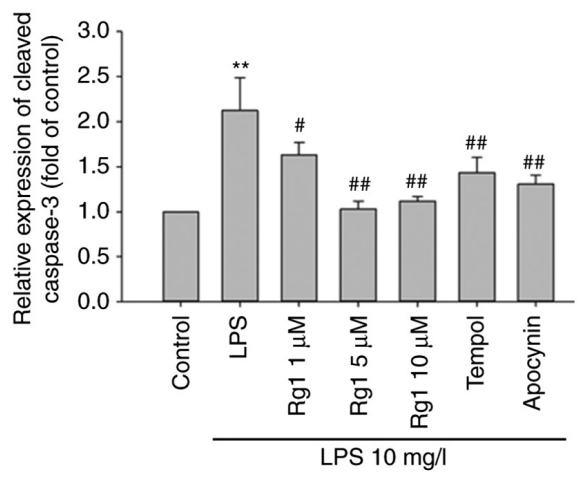

Figure 6. Effects of Rg1 on the expression levels of Bax, Bcl-2 and cleaved-caspase-3 in LPS-induced HT22 cells determined by western blotting. (A) The bands of Bax, Bcl-2 and cleaved-caspase-3 in LPS-induced HT22 cells. Quantitative analysis of (B) Bcl-2, (C) Bax and (D) cleaved-caspase-3 expression levels relative to the control. Results are expressed as mean $\pm \mathrm{SD}, \mathrm{n}=3 .{ }^{* *} \mathrm{P}<0.01$ vs. control group. ${ }^{\#} \mathrm{P}<0.05 ;{ }^{\# \#} \mathrm{P}<0.01 \mathrm{vs}$. LPS (10 mg/l) group. Rg1, ginsenoside $\mathrm{Rg} 1$; LPS, lipopolysaccharide.

vital in the progression of neurodegenerative diseases, including $\mathrm{AD}$ (43). In turn, the accumulation of ROS also could upregulate NOX expression. It has been reported that $\mathrm{H}_{2} \mathrm{O}_{2}$ treatment can significantly increase NOX2 expression in PC12 cells, a cell line similar to neurons (44). NOX is a complex membrane protein that is composed of membrane subunits of catalyzed gp91phox (NOX2) and p22phox, several regulatory catalytic subunits of p40phox, p47phox, p67phox and the small GTPase Rac. NOX2 is considered to be the major subtype of NOX in the brain, especially in neurons (45). A recent study suggested that inhibition of NOX activity could be a viable neuroprotective strategy for brain injury and senescence (46). It has been reported that walnut polyphenol extract protects against malathion- or chlorpyrifos-mediated immunotoxicity and inhibits oxidative damage by modulating the TLRx-NOX-ROS signaling pathway (47). In the present study, the results indicated that the expression of NOX2, p22phox and p47phox were significantly increased in LPS-induced HT22 cells. It was also seen that Rg1, tempol or apocynin treatment significantly decreased the expression of NOX2, p22phox and p47phox in LPS-induced HT22 cells. It was speculated that Rg1, tempol or apocynin treatment might downregulate NOX2 expression by decreasing ROS accumulation. The detailed mechanism of $\mathrm{Rg} 1$ on the regulation of NOX2 requires further study.

Increasing evidence suggests that inflammatory responses are an important feature and the leading cause of ageassociated neuronal damage (48). NLRP1 inflammasomes play a pivotal role in promoting inflammation throughout the body, and particularly in neurons $(49,50)$. The NLRP1 inflammasome is composed of NLRP1, apoptosis-associated speck-like protein (ASC) and procaspase-1. ASC can interact with NLRP1 and procaspase-1, and activate procaspase-1 to caspase- 1 , which cleaves the pro-IL-1 $\beta$ to generate the mature form of IL-1 $\beta$ (51). This effect can also be achieved by activating the $\mathrm{NF}-\kappa \mathrm{B}$ signaling pathway, which promotes the transcription of inflammation-associated genes, such as IL-1 $\beta$ and IL-6 (52). It has been reported that the inhibition of NLRP3 inflammasome activity could significantly decrease tissue inflammatory damage and inhibit apoptosis in LPS-induced acute kidney injury (53). A recent study reported that $\mathrm{Rg} 1$ could attenuate LPS-induced inflammation and apoptosis both in neonatal rat cardiomyocytes and septic mice and restore impaired cardiac function by blocking the TLR4/NF- $\kappa$ B/NLRP3 pathway (54). It has been reported that excessive ROS generation can activate the NLRP1 inflammasome and induce macrophage apoptosis in vitro and in vivo; although these effects can be significantly inhibited by pretreatment with ROS inhibitors (55). The latest study also showed that the inhibition of NOX significantly suppressed the production of pro-inflammatory cytokines, both in vitro and in vivo (56). However, it is still unknown whether Rg1 can protect against neuronal damage by inhibiting the expression of NOX2 and NLRP1 inflammasomes in LPS-induced HT22 cells. In the present study, it was found that LPS treatment significantly increased the expression of NLRP1, IL-1 $\beta$, cleaved caspase $-1, \mathrm{NF}-\kappa \mathrm{B}$ and $\mathrm{p}-\mathrm{NF}-\kappa \mathrm{B}$ in HT22 cells. The results also showed that $\mathrm{Rg} 1$, tempol and apocynin treatments significantly decreased the expression of NLRP1, IL-1 $\beta$, cleaved caspase-1, NF- $\kappa \mathrm{B}$ and $\mathrm{p}-\mathrm{NF}-\kappa \mathrm{B}$ in LPS-induced HT22 cells. Tempol, similar to catalase, is often used as a 
ROS scavenger in some models of neurodegeneration $(57,58)$. Apocynin can inhibit NOX2 $\left(\mathrm{IC}_{50}, \sim 10 \mu \mathrm{M}\right)$ and NOX4 $\left(\mathrm{IC}_{50}, \sim 200 \mu \mathrm{M}\right)$ to prevent ROS generation (59). The present results showed that $\mathrm{Rg} 1$ had a similar function to tempol and apocynin, suggesting that Rg1 might inhibit NLRP1 inflammasome activation by inhibiting NOX2 activity, decreasing ROS production in LPS-induced HT22 cells.

Apoptosis is a process of programmed cell suicide, which can be induced by senescence (60). It has been reported that both oxidative stress and inflammatory responses can induce cell apoptosis, which is involved in neuronal damage in neurodegenerative diseases, such as AD. Liu et al (61) reported that the inhibition of hippocampal neuron apoptosis could protect against neuron damage in ischemic stroke. Phosphatidylserine (PS) is located on the inner side of the cell membrane and turns to the outer surface of the cell membrane in early apoptotic cells. Annexin V can bind to phosphatidylserine exposed on the outside of the membrane of early apoptotic cells. Propidium iodide (PI), a nucleic acid dye, cannot penetrate the membrane of normal cells or early apoptotic cells, but can stain the nucleus of late apoptotic cells (62). The present study results indicated that $\mathrm{Rg} 1$ and apocynin treatment could inhibit apoptosis, shown by a decrease in both early and late apoptotic cells. However, tempol $(50 \mu \mathrm{M})$ treatment only showed a decrease in the early apoptotic cells in LPS-induced HT22 cells. The doses of tempol used (50-200 $\mu \mathrm{M})$ are commonly used in vitro to protect against cell apoptosis (63). In the present study, a smaller dose of tempol $(50 \mu \mathrm{M})$ was used, which may be the reason why only early apoptotic cells were inhibited. The B-cell lymphoma-2 (Bcl-2) family is known for their regulatory effects on apoptosis, and contains the anti-apoptotic gene, $\mathrm{Bcl}-2$, and the pro-apoptotic gene, Bcl-2 associated $\mathrm{X}$ protein (Bax). An increase in Bax can promote apoptosis, while an increase in $\mathrm{Bcl}-2$ can inhibit apoptosis. Caspase-3, the most critical protease for promoting the apoptosis cascade, plays the final pivotal role in apoptotic pathways (64). The present results showed that LPS exposure significantly increased the expression of Bax and cleaved caspase- 3 and decreased the expression of Bcl-2 in HT22 cells. However, treatment with Rg1, tempol or apocynin significantly decreased the expression levels of Bax and cleaved caspase- 3 and increased the expression level of Bcl-2 in LPS-induced HT22 cells. The results suggested that $\operatorname{Rg} 1$ could alleviate LPS-induced neuronal apoptosis via the regulation of the expression of Bax, Bcl-2 and cleaved caspase- 3 in HT22 cells.

In summary, the present study demonstrated that LPS exposure could significantly induce neuronal damage and apoptosis in HT22 cells. Rg1 treatment could significantly alleviate neuronal damage and apoptosis, and the mechanisms may be associated with the inhibition of NOX2 and NLRP1 inflammasome expression, since these were significantly increased in LPS-induced HT22 cells. However, the present study only observed the protective effect of Rg1 on LPS-induced neuronal damage in vitro, and the protective effect and mechanism in vivo warrant further investigation.

\section{Acknowledgements}

The authors would like to thank Mr. Dake Huang and Mr. Bao Li from the Synthetic Laboratory of Basic Medicine College, Anhui Medical University for their technical assistance.

\section{Funding}

This study was supported by the National Natural Science Foundation of China (grant nos. 81671384 and 81371329) and Natural science research projects of universities in Anhui province (grant no. KJ2019A0226).

\section{Availability of data and materials}

The datasets used and/or analyzed during the current study are available from the corresponding author on reasonable request.

\section{Authors' contributions}

YZ, SD and YC performed the experiments, analyzed the data, and were the major contributors in writing the manuscript. JZ, $\mathrm{ZF}$ and ZS collated the data. YH and XD contributed to the interpretation of the results. ZF and ZS confirm the authenticity of all the raw data. WL designed the study, critically revised the manuscript for intellectually important content and supervised the study. All authors read and approved the final submitted manuscript.

\section{Ethics approval and consent to participate}

Not applicable.

\section{Patient consent for publication}

Not applicable.

\section{Competing interests}

The authors declare that they have no competing interests.

\section{References}

1. Freeman LC and Ting JP: The pathogenic role of the inflammasome in neurodegenerative diseases. J Neurochem 136 (Suppl 1): S29-S38, 2016.

2. Boutajangout A, Lindberg H, Awwad A, Paul A, Baitalmal R, Almokyad I, Höidén-Guthenberg I, Gunneriusson E, Frejd FY, Härd T, et al: Affibody-mediated sequestration of amyloid $\beta$ demonstrates preventive efficacy in a transgenic Alzheimer's disease mouse model. Front Aging Neurosci 11: 64, 2019.

3. Zhan X, Stamova B, Jin LW, DeCarli C, Phinney B and Sharp FR: Gram-negative bacterial molecules associate with Alzheimer disease pathology. Neurology 87: 2324-2332, 2016.

4. Zhao Y, Jaber V and Lukiw WJ: Secretory products of the human GI tract microbiome and their potential impact on Alzheimer's disease (AD): Detection of lipopolysaccharide (LPS) in AD hippocampus. Front Cell Infect Microbiol 7: 318, 2017.

5. Ju IG, Choi JG, Kim N, Kwak C, Lee JK and Oh MS: Peucedani Japonici Radix ameliorates lipopolysaccharide-induced neuroinflammation by regulating microglial responses. Neurosci Lett 686: 161-167, 2018.

6. Zhou J, Yu W, Zhang M, Tian X, Li Y and Lü Y: Imbalance of microglial TLR4/TREM2 in LPS-treated APP/PS1 transgenic mice: A potential link between Alzheimer's disease and systemic inflammation. Neurochem Res 44: 1138-1151, 2019.

7. You LH, Yan CZ, Zheng BJ, Ci YZ, Chang SY, Yu P, Gao GF, Li HY, Dong TY and Chang YZ: Astrocyte hepcidin is a key factor in LPS-induced neuronal apoptosis. Cell Death Dis 8: e2676, 2017.

8. Ji YF, Wang D, Liu YR, Ma XR, Lu H and Zhang BA: MicroRNA-132 attenuates LPS-induced inflammatory injury by targeting TRAF6 in neuronal cell line HT-22. J Cell Biochem 119: 5528-5537, 2018 . 
9. Christensen LP and Christensen KB: The role of direct and indirect polyphenolic antioxidants in protection against oxidative stress. In: Polyphenols in Human Health and Disease. Watson RR, Preedy VR and Zibadi S (eds). Academic Press, San Diego, CA, pp289-309, 2014.

10. Bhat AH, Dar KB, Anees S, Zargar MA, Masood A, Sofi MA and Ganie SA: Oxidative stress, mitochondrial dysfunction and neurodegenerative diseases; a mechanistic insight. Biomed Pharmacother 74: 101-110, 2015.

11. Dasoveanu DC, Park HJ, Ly CL, Shipman WD, Chyou S, Kumar V, Tarlinton D, Ludewig B, Mehrara BJ and Lu TT: Lymph node stromal CCL2 limits antibody responses. Sci Immunol 5: eaaw0693, 2020

12. d'Avila JC, Siqueira LD, Mazeraud A, Azevedo EP, Foguel D, Castro-Faria-Neto HC, Sharshar T, Chrétien F and Bozza FA: Age-related cognitive impairment is associated with long-term neuroinflammation and oxidative stress in a mouse model of episodic systemic inflammation. J Neuroinflammation 15: 28, 2018

13. Fan LM, Cahill-Smith S, Geng L, Du J, Brooks G and Li JM: Aging-associated metabolic disorder induces Nox2 activation and oxidative damage of endothelial function. Free Radic Biol Med 108: 940-951, 2017.

14. Zotova E, Bharambe V, Cheaveau M, Morgan W, Holmes C, Harris S, Neal JW, Love S, Nicoll JA and Boche D: Inflammatory components in human Alzheimer's disease and after active amyloid- $\beta 42$ immunization. Brain 136: 2677-2696, 2013.

15. Abulafia DP, de Rivero Vaccari JP, Lozano JD, Lotocki G, Keane RW and Dietrich WD: Inhibition of the inflammasome complex reduces the inflammatory response after thromboembolic stroke in mice. J Cereb Blood Flow Metab 29: 534-544 2009.

16. Ma MW, Wang J, Dhandapani KM and Brann DW: NADPH oxidase 2 regulates NLRP3 inflammasome activation in the brain after traumatic brain injury. Oxid Med Cell Longev 2017: 6057609, 2017

17. Xu T, Sun L, Shen X, Chen Y, Yin Y, Zhang J, Huang D, Li W and Li W: NADPH oxidase 2-mediated NLRP1 inflammasome activation involves in neuronal senescence in hippocampal neurons in vitro. Int Immunopharmacol 69: 60-70, 2019.

18. Qiu Z, He Y, Ming H, Lei S, Leng Y and Xia ZY: Lipopolysaccharide (LPS) aggravates high glucose- and hypoxia/reoxygenation-induced injury through activating ROS-dependent NLRP3 inflammasome-mediated pyroptosis in H9C2 cardiomyocytes. J Diabetes Res 2019: 8151836, 2019.

19. Xiao Q, Zhang S, Ren H, Du R, Li J, Zhao J, Gao Y, Zhu Y and Huang W: Ginsenoside Rg1 alleviates ANIT-induced intrahepatic cholestasis in rats via activating farnesoid $\mathrm{X}$ receptor and regulating transporters and metabolic enzymes. Chem Biol Interact 324: 109062, 2020

20. Zhu G, Wang Y, Li J and Wang J: Chronic treatment with ginsenoside $\operatorname{Rg} 1$ promotes memory and hippocampal long-term potentiation in middle-aged mice. Neuroscience 292: 81-89, 2015.

21. Zhang YQ, Wang XB, Xue RR, Gao XX and Li W: Ginsenoside Rg1 attenuates chronic unpredictable mild stress-induced depressive-like effect via regulating NF- $\kappa \mathrm{B} / \mathrm{NLRP} 3$ pathway in rats. Neuroreport 30: 893-900, 2019.

22. Giuliani C: The flavonoid quercetin induces AP-1 activation in FRTL-5 thyroid cells. Antioxidants 8: 112, 2019.

23. Chen Y, Ding S, Zhang H, Sun Z, Shen X, Sun L, Yin Y, Qun S and $\mathrm{Li} \mathrm{W}$ : Protective effects of ginsenoside $\mathrm{Rg} 1$ on neuronal senescence due to inhibition of NOX2 and NLRP1 inflammasome activation in SAMP8 mice. J Funct Foods 65: 103713, 2020

24. Jin Y, Peng J, Wang X, Zhang D and Wang T: Ameliorative effect of ginsenoside Rg1 on lipopolysaccharide-induced cognitive impairment: Role of cholinergic system. Neurochem Res 42 : 1299-1307, 2017.

25. Crupi R, Impellizzeri D, Gugliandolo E, Cordaro M, Siracusa R, Britti D, Cuzzocrea S and Di Paola R: Effect of tempol, membrane-permeable free radical scavenger, on in vitro model of eye inflammation on rabbit corneal cells. J Ocul Pharmacol Ther 35: 571-577, 2019

26. Li M, Liu Z, Zhuan L, Wang T, Guo S, Wang S, Liu J and Ye Z: Effects of apocynin on oxidative stress and expression of apoptosis-related genes in testes of diabetic rats. Mol Med Rep 7: 47-52, 2013

27. Shen X, Dong X, Han Y, Li Y, Ding S, Zhang H, Sun Z, Yin Y, $\mathrm{Li}$ W and $\mathrm{Li}$ W: Ginsenoside Rg1 ameliorates glomerular fibrosis during kidney aging by inhibiting NOX4 and NLRP3 inflammasome activation in SAMP8 mice. Int Immunopharmacol 82: 106339, 2020.
28. Liu J, Li L and Suo WZ: HT22 hippocampal neuronal cell line possesses functional cholinergic properties. Life Sci 84: 267-271, 2009.

29. El-Far AH, Darwish NHE and Mousa SA: Senescent colon and breast cancer cells induced by doxorubicin exhibit enhanced sensitivity to curcumin, caffeine, and thymoquinone. Integr Cancer Ther 19: 1534735419901160, 2020.

30. Xu TZ, Shen XY, Sun LL, Chen YL, Zhang BQ, Huang DK and $\mathrm{Li}$ WZ: Ginsenoside $\mathrm{Rg} 1$ protects against $\mathrm{H}_{2} \mathrm{O}_{2}$-induced neuronal damage due to inhibition of the NLRP1 inflammasome signalling pathway in hippocampal neurons in vitro. Int $\mathrm{J}$ Mol Med 43: 717-726, 2019.

31. Zong Y, Ai QL, Zhong LM, Dai JN, Yang P, He Y, Sun J, Ling EA and Lu D: Ginsenoside Rg1 attenuates lipopolysaccharide-induced inflammatory responses via the phospholipase $\mathrm{C}-\gamma 1$ signaling pathway in murine BV-2 microglial cells. Curr Med Chem 19: 770-779, 2012.

32. Zanoni I, Bodio C, Broggi A, Ostuni R, Caccia M, Collini M, Venkatesh A, Spreafico R, Capuano G and Granucci F: Similarities and differences of innate immune responses elicited by smooth and rough LPS. Immunol Lett 142: 41-47, 2012.

33. Catorce MN and Gevorkian G: LPS-induced murine neuroinflammation model: Main features and suitability for pre-clinical assessment of nutraceuticals. Curr Neuropharmacol 14: 155-164, 2016.

34. Lopes PC: LPS and neuroinflammation: A matter of timing. Inflammopharmacology 24: 291-293, 2016.

35. Xu C, Hou B, He P, Ma P, Yang X, Yang X, Zhang L, Qiang G, Li W and Du G: Neuroprotective effect of salvianolic acid A against diabetic peripheral neuropathy through modulation of Nrf2. Oxid Med Cell Longev 2020: 6431459, 2020.

36. Velagapudi R, El-Bakoush A and Olajide OA: Activation of Nrf2 pathway contributes to neuroprotection by the dietary flavonoid tiliroside. Mol Neurobiol 55: 8103-8123, 2018.

37. Wan JZ, Wang R, Zhou ZY, Deng LL, Zhang CC, Liu CQ, Zhao HX, Yuan CF, He YM, Dun YY, et al: Saponins of Panax japonicus attenuate neuronal apoptosis through oxidative stress-related pathways and autophagy in natural aging rats. Curr Pharm Biotechnol 21, 2019

38. Wu J, Pan Z, Wang Z, Zhu W, Shen Y, Cui R, Lin J, Yu H, Wang Q, Qian J, et al: Ginsenoside Rg1 protection against $\beta$-amyloid peptide-induced neuronal apoptosis via estrogen receptor $\alpha$ and glucocorticoid receptor-dependent anti-protein nitration pathway. Neuropharmacology 63: 349-361, 2012.

39. Ma J, Liu J, Wang Q, Yu H, Chen Y and Xiang L: The beneficial effect of ginsenoside $\mathrm{Rg} 1$ on Schwann cells subjected to hydrogen peroxide induced oxidative injury. Int J Biol Sci 9: 624-636, 2013.

40. Xiang Y, Wang SH, Wang L, Wang ZL, Yao H, Chen LB and Wang YP: Effects of ginsenoside Rg1 regulating Wnt/ $\beta$-catenin signaling on neural stem cells to delay brain senescence. Stem Cells Int 2019: 5010184, 2019.

41. Liu JQ, Zhao M, Zhang Z, Cui LY, Zhou X, Zhang W, Chu SF, Zhang DY and Chen NH: Rg1 improves LPS-induced Parkinsonian symptoms in mice via inhibition of NF- $\mathrm{BB}$ signaling and modulation of M1/M2 polarization. Acta Pharmacol Sin 41: 523-534, 2020

42. Xu J, Wei X, Gao F, Zhong X, Guo R, Ji Y, Zhou X, Chen J, Yao P, Liu $X$ and Wei $X$ : Nicotinamide adenine dinucleotide phosphate oxidase 2-derived reactive oxygen species contribute to long-term potentiation of C-fiber-evoked field potentials in spinal dorsal horn and persistent mirror-image pain following high-frequency stimulus of the sciatic nerve. Pain 161: 758-772, 2020.

43. Wang Y, Lv W, Li Y, Liu D, He X and Liu T: Ampelopsin improves cognitive impairment in Alzheimer's disease and effects of inflammatory cytokines and oxidative stress in the hippocampus. Curr Alzheimer Res 17: 44-51, 2019.

44. Chen XH, Zhou X, Yang XY, Zhou ZB, Lu DH, Tang Y, Ling ZM, Zhou LH and Feng X: Propofol protects against $\mathrm{H} 2 \mathrm{O} 2$-induced oxidative injury in differentiated PC12 cells via inhibition of $\mathrm{Ca}(2+)$-dependent NADPH oxidase. Cell Mol Neurobiol 36: 541-551, 2016.

45. Sun L, Chen Y, Shen X, Xu T, Yin Y, Zhang H, Ding S, Zhao Y, Zhang Y, Guan Y and Li W: Inhibition of NOX2-NLRP1 signaling pathway protects against chronic glucocorticoids exposure-induced hippocampal neuronal damage. Int Immunopharmacol 74: 105721, 2019.

46. Tenkorang MAA, Duong P and Cunningham RL: NADPH oxidase mediates membrane androgen receptor-induced neurodegeneration. Endocrinology 160: 947-963, 2019.

47. Zhao Y, Fan C, Zhang A, Zhang Y, Wang F, Weng Q and $\mathrm{Xu} \mathrm{M}$ : Walnut polyphenol extract protects against Malathionand chlorpyrifos-induced immunotoxicity by modulating TLRx-NOX-ROS. Nutrients 12: 616, 2020. 
48. Liu L and Chan C: The role of inflammasome in Alzheimer's disease. Ageing Res Rev 15: 6-15, 2014.

49. Yin Y, Yan Y, Jiang X, Mai J, Chen NC, Wang H and Yang XF. Inflammasomes are differentially expressed in cardiovascular and other tissues. Int J Immunopathol Pharmacol 22: 311-322, 2009.

50. Tan CC, Zhang JG, Tan MS, Chen H, Meng DW, Jiang T, Meng XF, Li Y, Sun Z, Li MM, et al: NLRP1 inflammasome is activated in patients with medial temporal lobe epilepsy and contributes to neuronal pyroptosis in amygdala kindling-induced rat model. J Neuroinflammation 12: 18, 2015.

51. de Rivero Vaccari JP, Dietrich WD and Keane RW: Therapeutics targeting the inflammasome after central nervous system injury. Transl Res 167: 35-45, 2016.

52. Martins JD, Liberal J, Silva A, Ferreira I, Neves BM and Cruz MT: Autophagy and inflammasome interplay. DNA Cell Biol 34: 274-281, 2015.

53. Gao Q and Zhu H: The overexpression of sirtuin1 (SIRT1) alleviated lipopolysaccharide (LPS)-induced acute kidney injury (AKI) via inhibiting the activation of nucleotide-binding oligomerization domain-like receptors (NLR) family pyrin domain containing 3 (NLRP3) inflammasome. Med Sci Monit 25: 2718-2726, 2019.

54. Luo M, Yan D, Sun Q, Tao J, Xu L, Sun H and Zhao H: Ginsenoside $\operatorname{Rg} 1$ attenuates cardiomyocyte apoptosis and inflammation via the TLR4/NF- $\kappa$ B/NLRP3 pathway. J Cell Biochem 121: 2994-3004, 2020.

55. Gan P, Gao Z, Zhao X and Qi G: Surfactin inducing mitochondria-dependent ROS to activate MAPKs, NF- $\kappa \mathrm{B}$ and inflammasomes in macrophages for adjuvant activity. Sci Rep 6 : 39303, 2016.

56. Peng X, Yang Y, Tang L, Wan J, Dai J, Li L, Huang J, Shen Y, Lin L, Gong X and Zhang L: Therapeutic benefits of apocynin in mice with lipopolysaccharide/D-galactosamine-induced acute liver injury via suppression of the late stage pro-apoptotic AMPK/JNK pathway. Biomed Pharmacother 125: 110020, 2020.
57. Youn CK, Kim J, Jo ER, Oh J, Do NY and Cho SI: Protective effect of tempol against cisplatin-induced ototoxicity. Int J Mol Sci 17: 1931, 2016.

58. Wilcox CS: Effects of tempol and redox-cycling nitroxides in models of oxidative stress. Pharmacol Ther 126: 119-145, 2010.

59. Serrander L, Cartier L, Bedard K, Banfi B, Lardy B, Plastre O, Sienkiewicz A, Fórró L, Schlegel W and Krause KH: NOX4 activity is determined by mRNA levels and reveals a unique pattern of ROS generation. Biochem J 406: 105-114, 2007.

60. Barman J, Kumar R, Saha G, Tiwari K and Dubey VK: Apoptosis: Mediator molecules, interplay with other cell death processes and therapeutic potentials. Curr Pharm Biotechnol 16: 644-663, 2018.

61. Liu QS, Deng R, Li S, Li X, Li K, Kebaituli G, Li X and Liu R: Ellagic acid protects against neuron damage in ischemic stroke through regulating the ratio of $\mathrm{Bcl}-2 / \mathrm{Bax}$ expression. Appl Physiol Nutr Metab 42: 855-860, 2017.

62. Zhou H, Wang Q, Yuan D, Wang J, Huang Y, Wu H, Jian J, Yang D, Huang N, Haisch C, Jiang Z and Chen S: Early apoptosis real-time detection by label-free SERS based on externalized phosphatidylserine. Analyst 141: 4293-4298, 2016.

63. Qi C, Liu X, Xiong T and Wang D: Tempol prevents isoprenaline-induced takotsubo syndrome via the reactive oxygen species/mitochondrial/anti-apoptosis/p38 MAPK pathway. Eur J Pharmacol 886: 173439, 2020.

64. Ju Y, Su Y, Chen Q, Ma K, Ji T, Wang Z, Li W and Li W: Protective effects of Astragaloside IV on endoplasmic reticulum stress-induced renal tubular epithelial cells apoptosis in type 2 diabetic nephropathy rats. Biomed Pharmacother 109: 84-92, 2019.

(i) $(9)$ This work is licensed under a Creative Commons Attribution-NonCommercial-NoDerivatives 4.0 International (CC BY-NC-ND 4.0) License. 